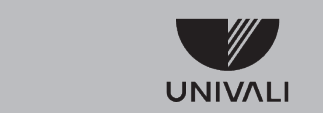

UNIVERSIDADE DO VALE DO ITAJAí

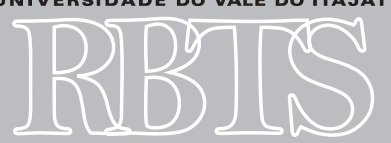

Revista Brasileira de Tecnologias Sociais
1 Enfermeira. Mestre em Saúde

e Gestão do Trabalho pela Universidade do Vale do Itajaí. Docente do Curso de Graduação em Enfermagem da Universidade do Vale do Itajaí. E-mail: thais. faveroalves@gmail.com

2 Dentista. Doutora em Saúde Coletiva pela Universidade Federal de Santa Catarina. Docente do Curso de Mestrado em Saúde e Gestão do Trabalho e do Curso de Graduação em Odontologia. E-mail: rita.lima@, univali.br

\section{Interesse público na saúde: saúde suplementar e hegemonia mercantilista}

\section{Public interest in health: supplementary health and mecantilist hegemony}

\author{
Thaís Fávero ALVES ${ }^{1} \&$ Rita de Cássia Gabrielli Souza LiMA²
}

RESUMO: O presente artigo analisou os sentidos atribuídos à expressão 'interesse público' na saúde, apresentada como finalidade institucional da Agência Nacional de Saúde Suplementar em sua Lei de criação. Para tal, realizou-se pesquisa em documentos legais e infralegais relacionados à origem da Agência e suas atividades regulatórias, no recorte histórico de 1985 a 2000. Concluiu-se que, no Brasil, o interesse público carrega sentidos mercadológicos desde a década de 1920, com a instituição das CAPs, intensificando-se no período da ditadura militar e chegando ao seu ápice com a regulação e a oficialização deste mercado nos governos neoliberais instituídos no País a partir dos anos 1990 .

Palavras-chave: Saúde Suplementar; Sistema Único de Saúde; Mercado de Serviços de Saúde.

ABSTRACT: This article analyzes the meanings attributed to the term 'public interest' in health, presented as an institutional purpose of the Agência Nacional de Saúde Suplementar (National Agency for Supplementary Health) in its Law of creation. To this end, research was carried out in legal and infralegal documents related to the origin of the Agency and its regulatory activities in the historical period 1985-2000. It was concluded that in Brazil, the public interest has carried mercantilist meanings since the 1920s, intensifying during the military dictatorship and reaching their apex with the regulation and formalization of this market in the neoliberal governments established in the country from the $1990 \mathrm{~s}$.

Key-words: Supplementary Health; Unified Health System; Marketing of Health Services. 
UNIVALI

UNIVERSIDADE DO VALE DO ITAJAÍ

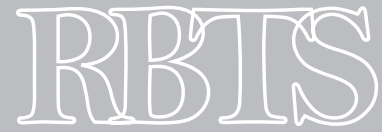

Revista Brasileira de Tecnologias Sociais 


\section{INTRODUÇÃO}

A conquista da cidadania, em seu sentido mais profundo, o de participar das decisões políticas e da vida do Estado como um de seus membros, materializou-se de muitas formas no Brasil, no período de redemocratização do País, em especial por meio do texto instituído na Constituição Cidadã de 1988. Dentre as principais manifestações escritas que anunciavam novos tempos à população em um novo projeto de Estado - agora democrático e de direito -, está a conquista do direito universal à saúde.

Esta conquista, fruto direto da militância do Movimento de Reforma Sanitária iniciado na década de 1970, teve como um de seus momentos mais emblemáticos a criação do Sistema Único de Saúde (SUS), que representava os anseios da quebra de velhos paradigmas biologicistas e privatistas, em prol de conceitos socialmente mais justos, como o das práticas de medicina social.

Hoje, pode-se dizer que o SUS está de pé (CUETO et al., 2014). No entanto, é sabido que a saúde que se vivencia no País está, há muito, distante do idealizado. Muitas das questões que são cruciais à sobrevivência do Sistema estão ligadas às inconsistências e às incoerências da relação entre o sistema público e a iniciativa privada, a exemplo de financiamento e de incentivos governamentais.

Isto se dá, aparentemente, devido à manutenção de uma hegemonia privatista nos serviços médicos e especializados, iniciada no Brasil na década de 1920, continuada na "Era Vargas" e fortalecida na ditadura militar por meio das reformas curriculares implementadas a partir de 1968, bem como da compra crescente, por parte do Estado, de serviços privados financiados com dinheiro público. Esta hegemonia, apesar das mudanças políticas enfrentadas pelo País, mantémse firme mesmo na existência do direito social conquistado ao acesso universal à saúde.

A composição mista que se tem no sistema de saúde somente é possível devido à própria Constituição de 1988 que, em sua seção II, afirma no artigo 199 que a "assistência à saúde é livre à iniciativa privada". Ainda neste artigo, $\S 1^{\circ}$, lê-se que: "As instituições privadas poderão participar de forma complementar do sistema único de saúde, (...) tendo preferência as entidades filantrópicas e as sem fins lucrativos" (BRASIL, 1988).

Mantendo-se coerente à Constituição de 1988, a Lei 8.080 de 19 de setembro de 1990, também reconhecida como Lei Orgânica da Saúde, dispõe de um capítulo específico para esclarecer sobre a participação complementar, conforme disposto em seu artigo 24: "Quando as suas disponibilidades forem insuficientes para garantir a cobertura assistencial à população de uma determinada área, o Sistema Único de Saúde (SUS) poderá recorrer aos serviços ofertados pela iniciativa privada" (BRASIL, 1990).

Nos anos 90, com a reforma neoliberal, criou-se o processo de 'publicização' na saúde brasileira que, na verdade, "serviu para torná-lo menos público" (PAIM; TEIXEIRA, 2007, p. 1824). Foi por meio da Reforma do Estado (BRASIL, 1995) que o conceito de agência reguladora foi implementado no País. Este documento (da reforma do Estado) embasou a criação de órgãos vinculados ao Ministério da Saúde que, até os dias atuais, alteram significativamente a estrutura do Sistema no Brasil.

Somente dez anos após a efetivação do Sistema Único de Saúde como um direito social conquistado é que se regulamentou o setor privado por meio da criação da Agência Nacional de Saúde Suplementar (ANS). A ANS, por sua vez, é um exemplo concreto de agência reguladora surgida em decorrência da reforma neoliberal. 
Os ventos neoliberais, dos anos 90, propagaram a necessidade de os Estados capitalistas propiciarem uma harmoniosa convivência entre o Estado e o mercado. Soprados na Europa desde décadas anteriores (final de 60, décadas de 70 e de 80), esses ventos seduziram inúmeras realidades capitalistas. Na Itália, por exemplo, ventos neoliberais deflagraram a escolha estatal por uma reforma administrativa, em 1992, chamada Reforma De Lorenzo Garavaglia que, instituída por decreto, consistiu em executar um modelo de gestão sanitária regionalizada, comandada por diretores gerais, sanitários e distritais (CAVICCHI, 2005; MAPELLI, 1999).

Devido à progressiva submissão do sistema sanitário italiano ao mercado, indústria e tecnologia, cujas raízes estão no final da década de 1960 (CAVICCHI, 2005), novas demandas de necessidades foram incorporadas pela sociedade. Este novo cenário levou o país a optar pela regionalização através de agências sanitárias com o argumento de que precisava encontrar saídas para gerir o aumento desenfreado da dita despesa em saúde. Ou seja, ao contrário de aprimorar o Serviço Sanitário Nacional, conquistado em 1978 pela Reforma Sanitária italiana, o país optou pela regionalização via agências como via institucional para intervir na despesa e acomodar o consumo sanitário aos recursos existentes (CAVICCHI, 2005; MAPELLI, 1999).

Este fato da história sanitária italiana foi gerado na dificuldade da Itália materializar a sua Reforma Sanitária, nos anos subsequentes a 1978, quando o Serviço Sanitário Nacional foi conquistado pelo Movimento Sanitário italiano. Dois obstáculos foram patentes: o país havia tido seis diferentes governos pertencentes às duas maiores forças políticas concorrentes (de 1978 a 1992) e o país estava embriagado pelo ideário de abertura do Estado para o mercado (COSMACINI, 2005). Em outra abordagem, a força neoliberal levou o Estado italiano a diminuir a regulação de suas políticas sociais e o Welfare, sistema predominantemente público, passou para um sistema Welfare misto, estruturado em três eixos: público, mercado e terceiro setor ${ }^{1}$ (UNIVERSITÀ DEL VOLONTARIATO, 2001). E aqui um questionamento: a crise era do Estado ou do papel do Estado? (CAVICCHI, 2005).

Sob os efeitos de ventos neoliberais, a Lei brasileira $n^{\circ} 9.961$ de 28 de janeiro de 2000 , que cria a ANS, traz como finalidade institucional da Agência a "promoção da defesa do interesse público na assistência suplementar à saúde” e, ainda, vincula a mesma ao Ministério da Saúde, como sendo uma extensão das ações do governo federal à iniciativa privada, na defesa deste dito “interesse público” (BRASIL, 2000).

Um ponto crucial, porém ainda não esclarecido em legislação vigente hoje no País, é a transição da nomenclatura contida na Constituição e Lei Orgânica do SUS como "complementar" para "suplementar" dez anos depois, através da Lei de criação da ANS. A princípio, essa inconsistência pode passar despercebida pela maioria dos usuários do sistema de saúde brasileiro; contudo a troca de termos similares (mas, não iguais) se configura como uma das várias interrogações que se tem ainda hoje sobre a real função da atuação da iniciativa privada no SUS.

Da mesma maneira que hoje a regulação do Setor é vinculada ao Ministério da Saúde por meio de núcleo específico, os antecedentes da saúde suplementar no Brasil também estiveram diretamente vinculados a políticas públicas nacionais. Um marco essencial para a existência dos 'planos de saúde' como se conhece hoje foi a Lei Eloy Chaves, de 1923, que instituiu as Caixas de Aposentadoria e Pensão (CAPs), responsáveis não somente por questões previdenciárias, mas também por fornecimento de medicamentos e assistência médica (MERCADANTE, 2002; ANS, 2016; OLIVEIRA et al., 1989).

1 Terceiro setor: formado pelo setor Nonprofit, por cooperativas sociais, associações e fundações de direito privado, sociedade de mútuo auxílio, organizações de voluntariado e associações de promoção social (UNIVERSITÀ DEL VOLONTARIATO, 2001). 
Pouco tempo depois da Eloy Chaves, no início da década de 30, foram criados como forma de minimizar a disparidade entre as CAPs, os Institutos de Aposentadoria e Pensão (IAPs), que reuniam por categoria profissional os trabalhadores em um mesmo Instituto (MERCADANTE, 2002; OLIVEIRA et al., 1989). Da unificação dos IAPs, surge em 1965 o Instituto Nacional de Previdência Social (INPS) e, posteriormente, no final da década de 70, o Instituto Nacional de Assistência Médica da Previdência Social (INAMPS), caracterizado pela compra de serviços privados por parte do Estado, em especial médico-hospitalares (REIS et al., S. I.).

Essa característica de compra de serviços especializados e médico-hospitalares privados por parte do Estado, através de recursos públicos, faz-se presente ainda nos dias atuais, mesmo após o advento do SUS. Isto se dá em função do mix público-privado do Sistema de Saúde efetivado após a Constituição de 1988, bem como da manutenção de comportamentos estatais de privilégio a serviços privados, existentes desde 1920 e aperfeiçoados com o tempo, resistindo a mudanças no Estado, devido ao fomento e aos interesses de governos transitórios.

Instituições bastante conhecidas do setor - hoje - denominado suplementar na saúde, a exemplo da CASSI, ABRAMGE, Golden Cross, AMIL e Unimed, foram instituídas em sua maioria entre os anos de 1930 a 1982, da "Era Vargas" ao fim da ditadura militar (SOUZA, 2014), fortalecendo a ideia de que nos períodos de instabilidade democrática ou, ainda, de total ausência dela, a segmentação privada na saúde obteve 'chão’ para esta expansão vislumbrada até os dias atuais; sendo o artigo 199 da Constituição Federal apenas a abertura legal do Estado brasileiro em transição democrática para a oficialização do setor privado.

Desta forma, nota-se, também, que o período político econômico instaurado a partir de 1990 com o plano de transição ao neoliberalismo iniciado pelo governo Collor e fortalecido pelos governos Fernando Henrique Cardoso (FHC) foram voltados basicamente - no âmbito da assistência privada à saúde - para a regulação deste setor e deste mercado.

Em linhas gerais, para o setor suplementar, pode-se dizer que: começou na República Velha, fortaleceu-se na ditadura militar e regulamentou-se no neoliberalismo.

No momento político atual vivido no País, em meio a uma transição ideológica de governos, faz-se importante a retomada da reflexão acerca destas interrogações que permeiam a relação público-privada na saúde brasileira, em especial da real função do setor suplementar para com o Sistema Público: afinal, para o órgão regulador dos planos de saúde no Brasil, a ANS, o que é defender o interesse público na saúde? Quais ações da Agência, hoje, servem a este fim?

Diante deste cenário complexo na saúde brasileira, caracterizado pelo histórico misto entre público e privado na contratação e na prestação de serviços à população, este artigo assume como desafio a análise dos sentidos atribuídos à expressão 'interesse público' na saúde, pelo setor suplementar, representado em especial em documentos relacionados à origem de sua entidade reguladora, a ANS.

\section{METODOLOGIA}

O presente manuscrito é fruto de uma pesquisa de natureza qualitativa aprovada previamente em Comitê de Ética em Pesquisa sob o parecer de $\mathrm{n}^{\circ}$ 1.358.527. A proposta consistiu em analisar os sentidos atribuídos ao termo 'interesse público’ na saúde, utilizado como finalidade institucional da Agência Nacional de Saúde Suplementar em sua lei de criação. 
Optou-se pela busca de sentidos, ao contrário de significados, apoiando-se em Vigotski (2001), que discorre sobre o caráter estático dos significados gerais e das subjetividades dos sentidos, atribuídos pelos sujeitos a determinado tema, em determinado contexto. $\mathrm{O}$ tema a ser aqui analisado refere-se à expressão 'interesse público’ na saúde, em contexto específico da saúde suplementar, através de documentação relacionada à origem de seu órgão regulador, a ANS.

Para tal atribuição de sentidos, elegeu-se a pesquisa documental como instrumentalização da natureza qualitativa, sendo realizada através da leitura de documentos legais, infralegais e documentos marginais relacionados à origem e à oficialização do setor suplementar na saúde, representado pela ANS, em recorte histórico de 1985 a 2000.

O recorte histórico eleito justifica-se na existência de um período de importantes fatos políticos, históricos e sociais aos brasileiros, em especial no âmbito das práticas de saúde. Tem-se, desta maneira, a transição democrática do País no final da década de 1980; a saúde conquistada como direito na Constituição Cidadã, associada a artigo específico que discorre sobre a liberdade de ação da iniciativa privada no setor; as leis orgânicas da saúde e de direito do consumidor, que configuram base jurídica para as práticas do domínio privado no período pré-regulação; e, finalizando, a importação do conceito de agência ao Brasil, no neoliberalismo, que culminou na definição conceitual sobre as operadoras de planos de saúde e a Agência regulamentadora - ANS.

Os documentos aqui analisados não foram eleitos aleatoriamente, mas se configuram como fruto de intensa leitura durante o processo da construção do trabalho, no qual foi possível acumular uma bagagem teórica que, organicamente, culminou nesta tentativa de "reconstrução" através de pesquisa documental, da história da saúde suplementar no recorte temporal eleito, bem como na análise dos sentidos atribuídos por este domínio a interesse público.

No Quadro 01, encontram-se descritos por título, data e relevância histórica para a pesquisa os documentos analisados neste trabalho.

Quadro 01: Documento analisado, por ano e relevância para a pesquisa

\begin{tabular}{|l|c|c|}
\hline Documento & Ano & Relevância \\
\hline Constituição Federal & 1988 & Garante liberdade de ação à iniciativa privada. \\
\hline Lei n ${ }^{\circ} 8.080$ & 1990 & $\begin{array}{c}\text { Organiza as ações de saúde no País, públicas e } \\
\text { privadas. }\end{array}$ \\
\hline Lei no 8.078 & 1990 & $\begin{array}{c}\text { Origem do Código de Defesa do Consumidor, } \\
\text { uma das bases jurídicas para a criação da ANS. }\end{array}$ \\
\hline $\begin{array}{l}\text { Plano Diretor de Reforma do } \\
\text { Aparelho do Estado }\end{array}$ & 1995 & $\begin{array}{c}\text { Importa o conceito de Agência Reguladora } \\
\text { ao Brasil no processo de abertura do País ao } \\
\text { neoliberalismo. }\end{array}$ \\
\hline Lei n ${ }^{\circ} 9.656$ & 1998 & $\begin{array}{c}\text { Dispõe sobre os planos e os seguros privados de } \\
\text { assistência à saúde. }\end{array}$ \\
\hline Lei n $^{\circ} 9.961$ & 2000 & Cria a Agência Nacional de Saúde Suplementar. \\
\hline
\end{tabular}

Fonte: As autoras.

À leitura dos documentos eleitos, procedeu-se, com repetição, a fim de distanciar-se das preconcepções das autoras sobre a temática trabalhada, visando à composição da análise dos sentidos buscada. A operacionalização da análise não se deu de forma estruturada em tabelas ou sistemas específicos, mas através de grifos de pontos específicos que representassem, de alguma forma, elementos de 'interesse público’ em seu conteúdo. Assim, da leitura e dos grifos realizados, 
emergiu uma categoria analítica, que permeou toda a documentação lida no recorte histórico entre 1985 a 2000: mercadoria.

\section{RESULTADOS E DISCUSSÃO}

Como este estudo se refere, em sua maioria, a documentos legais, evitou-se a utilização excessiva de citações diretas, pois a linguagem jurídica já é, em si só, um desafio a ser transposto. Assim, optou-se pela utilização de texto corrido, no qual se tentará "contar a história” da regulamentação da iniciativa privada na saúde brasileira, desde 1985 até 2000, através dos principais marcos históricos deste setor.

A discussão apresentada a seguir é resultado direto da reflexão entre os documentos oficiais, ao longo do tempo, associados ao posicionamento das autoras, acerca da atual conjuntura delineada no campo da saúde a partir destas legislações. Da relação entre as distintas culturas políticas (entre a cultura expressa nos documentos e a das autoras) (DE MARTINO, 1953) emergiu a compreensão de que as inserções do Estado, através de leis sobre a iniciativa privada na saúde, voltaram-se a um único fim ao longo do período estudado - mercadoria -. Este fim, que é o resumo, em uma única palavra, de como a saúde vem sendo tratada no Brasil ao longo dos anos, representa a categoria analítica do estudo: "Mercadoria" 2

\subsection{MERCADORIA}

Quaisquer discussões que envolvam saúde no Brasil, tanto sobre estruturas públicas quanto privadas, devem ser permeadas pelo marco histórico da Constituição Cidadã, de 1988, que considera, em seu artigo 196, saúde como direito de todos e dever do Estado (BRASIL, 1988). Esta frase impactante é resultado de intensas lutas do Movimento de Reforma Sanitária, que associou coletivos organizados, lideranças políticas e religiosas, bem como sociedade civil na militância pela conquista deste direito social.

A Constituição Federal, além do direito à saúde, caracteriza-se pela representação textual de um novo projeto de sociedade, democrático, de direito e que passasse a tratar seus cidadãos com respeito, permitindo-lhes, através de políticas sociais e econômicas, condições dignas de vida e, além disso, figura como objetivo da República a construção de uma sociedade livre, justa e solidária (BRASIL, 1988).

Contudo, hoje se vê que, como historicamente posto no Brasil, aquilo que se escreve não é, necessariamente, o que se lê na prática cotidiana. Na própria Constituição, Seção II, específica da saúde, o artigo 199 traz a informação de que "a assistência à saúde é livre à iniciativa privada” (BRASIL, 1988) sem muitas delongas e/ou explicações de como isto se daria no futuro. Sabe-se, apenas, que este artigo 199 existiria devido a uma teórica liberdade de escolha a ser conferida aos cidadãos.

A análise dos dados apontou que, apesar de garantir direitos imprescindíveis a uma sociedade com objetivos de justiça social, o texto Constitucional dispôs que as conquistas sociais exigiriam regulamentação. Neste sentido, ele se manteve aberto o suficiente para que fosse necessária a criação de uma série de Leis Orgânicas, aquelas responsáveis por especificar como estes direitos seriam geridos e operacionalizados pelo Estado.

2 Segundo dicionário Michaelis de língua portuguesa: 1 Aquilo que é objeto de compra ou venda. 2 Aquilo que se comprou e que se expõe à venda. (MICHAELIS, 2016). 
A mais conhecida no âmbito das políticas de saúde é a Lei $n^{\circ}$ 8.080/90, que dispõe sobre a organização e o funcionamento dos serviços de saúde no Brasil, inclusive sobre a relação entre os domínios público e privado. Esta lei, conhecida como Lei Orgânica da Saúde (LOS), discorre em capítulo específico sobre a participação da iniciativa privada no Sistema de Saúde nacional. O documento expõe as informações mais relevantes para o estudo da futura saúde 'suplementar', quando assinala que o setor privado poderá atuar como 'complementar' aos serviços públicos, sempre que este se mostrar de disponibilidade insuficiente para cobertura de uma determinada população. Observa-se, ainda, que a preferência para este tipo de relação complementar de serviços seria concedida às instituições filantrópicas e sem fins lucrativos (BRASIL, 1990).

Um esboço de discussão a respeito da inconclusiva nomenclatura do setor foi realizado por Werneck, ao admitir que os poucos estudos sobre o setor suplementar no Brasil contribuem para a falta de entendimento acerca de seu real papel para com o sistema público: "Complementar e suplementar são adjetivos antônimos. 'Complementar' refere-se àquilo que falta para um todo; enquanto 'suplementar' àquilo que excede o todo" (WERNECK, 2010, p.8). Contudo, o debate sobre esta questão, em sua totalidade, ainda é escasso se comparado à magnitude desta relação.

Concordando com o assentimento acima, observa-se que o texto presente na Lei 8.080 é coerente à definição de 'complementar' para a iniciativa privada, uma vez que este serviço somente deveria ser contratado na insuficiência do setor público, ou seja, na função de complementar aquilo que lhe é momentaneamente faltante. Entretanto, é indiscutível que a atual conformação do Sistema de Saúde, como este se põe na atualidade considerando a relação mista entre público e privado, é muito mais complexa do que discorre a LOS.

Hoje, da mesma maneira que o Sistema Único de Saúde se apresenta como um dos maiores sistemas públicos de saúde do mundo (BRASIL, 2016), a existência da saúde suplementar no Brasil delineou um cenário em que o setor brasileiro de planos e seguros de saúde é um dos maiores sistemas privados de saúde do mundo (ANS, 2016). O que parece, no mínimo, uma grande incoerência - como é possível ter um dos maiores sistemas públicos do mundo, que só deveria utilizar estruturas privadas esporadicamente e, simultaneamente, possuir um dos maiores serviços privados mundialmente conhecido?

A grande questão, diante desta problemática de significação da iniciativa privada diante do sistema público, será definir, como sociedade civil, que tipo de assistência privada se quer que coexista com o Sistema Único - complementar ou suplementar? Exclui-se, neste ponto específico da pesquisa, a discussão sobre a necessidade de existência ou não de liberdade à iniciativa privada, uma vez que esta já se tornou preceito à nação na Constituição Federal, mas se pauta a reflexão necessária acerca da dimensão da utilização destes serviços.

É importante que este debate ocorra com maior intensidade na atualidade, afinal, enquanto a sociedade brasileira usuária do SUS vivencia em todo território nacional constantes crises no Sistema Único de Saúde brasileiro através de subfinanciamento e, em especial, gestões corruptas (tripartite) atreladas ao mau uso do dinheiro público, a saúde suplementar comemora seus números que, apesar da crise econômica, se mantêm em crescimento considerável no País.

Prova concreta deste fato se dá mediante aos dados do próprio setor suplementar. Em dezembro de 2014 foram registrados pela ANS mais de 50 milhões de vínculos de beneficiários a planos privados de assistência médica. No mesmo ano a receita de contraprestações de operadoras médico-hospitalares atingiu $\mathrm{R} \$ 125$ bilhões de reais, enquanto as despesas assistenciais totalizaram 
$\mathrm{R} \$ 106$ bilhões, estima-se um aumento das receitas de contraprestações em 14,7\% se comparado às de 2013 (BRASIL, 2015).

Sabe-se que, na atual crise econômica vivida pelo Brasil, há uma grande preocupação do setor privado em fidelizar seus beneficiários aos planos já contratados por meio da oferta de serviços diferenciados do usual. Também são conhecidas algumas estratégias utilizadas para contenção de custos assistenciais na saúde suplementar, a exemplo da apropriação de termos como 'médico de família', 'promoção da saúde’ e ‘atenção integral à saúde', tradicionalmente utilizados pelo SUS (SILVA et al., 2015).

Uma patente de que o setor saúde é tratado historicamente como algo lucrativo é que algumas instituições hoje, reconhecidas pelo atendimento privado e/ou por convênios, a exemplo da Golden Cross e Hospital Albert Einstein, foram instituídas como sendo sem fins lucrativos e usufruíam dos benefícios de ser complementar ao setor público, como o não pagamento de impostos (SANTOS, 1992).

Esta característica de lucratividade do setor pode ter suas bases também na Constituição Federal, que ao instituir como objetivos da República a liberdade de escolha e livre iniciativa, argumentou sobre o papel do Estado acerca da defesa do consumidor. Este dito 'consumidor' na Constituição acabou sendo utilizado até a atualidade para dirigir-se ao cidadão que adquire serviços prestados pelo setor de saúde suplementar.

Da mesma forma que foi necessária a criação da LOS após o advento da Constituição Cidadã, o consumidor a ser defendido pelo Estado também foi regulamentado através de Lei Orgânica, a nº 8.078/90, origem legal do conhecido Código de Defesa do Consumidor (CDC). Esta Lei, de 11 de setembro de 1990, além de outras providências, dispõe sobre a proteção do consumidor (BRASIL, 1990) e incita em vários momentos da legislação a chamada 'culpa exclusiva do consumidor'.

A Lei que deu origem ao CDC é considerada um dos marcos legais para a existência da regulação ao setor suplementar hoje conhecido, isto porque, antes da criação de uma Agência específica para a fiscalização das operadoras de planos de saúde, era através deste Código que os cidadãos que contratavam planos de saúde buscavam ações judiciais ou Procon's, em caso de abusos das operadoras contratadas (IDEC, S/D).

Lamentavelmente, é também às legislações como esta que, muitas operadoras e, em especial, profissionais médicos, recorrem para se defender de ações judiciais abertas por pacientes ou beneficiários. Conforme jurisprudência consultada na área, estas ações judiciais, quando ganhas pelos profissionais de saúde, alegam sempre o fator 'culpa exclusiva do consumidor', de acordo com o regimento da Lei $n^{\circ} 8.078 / 90$, em especial no artigo $14^{\circ}, \S 3^{\circ}$ item II que, resumidamente, explanam: ser o fornecedor do serviço o responsável, na existência de culpa ou não, pelos danos causados ao consumidor, inclusive por informações insuficientes ou inadequadas, porém este mesmo fornecedor (no caso discutido aqui as operadoras e profissionais médicos) será isento desta culpa nos casos de culpa exclusiva do consumidor ou de terceiros (BRASIL, 1990).

Na tratativa jurídica acerca da responsabilidade do paciente é possível encontrar: “(...) se estes não obedecem à prescrição médica, podem não ter sucesso no tratamento a que se submeteram, sendo estes os culpados por tal insucesso, e não o médico/odontólogo que após anos de estudo científico foi submetido a risco pelo paciente” (WEINGARTNER, 2012). 
Aparentemente, o que se apresenta nesta postura defensiva é a conhecida terceirização da culpa ou, ainda, a culpabilização do sujeito por aquilo que não se consegue alterar na condição de saúde de alguém. Esta postura, de cunho estritamente biologicista e típica do culto à sociedade de riscos, nega o conceito de saúde impresso na Constituição Federal após intensa militância do Movimento de Reforma Sanitária, o que indica grande divergência entre os estilos de pensamento (DA ROS, 2000) componentes das bases históricas e legais das concepções de saúde impressas pelo MRS e o executado por alguns profissionais e planos de saúde com base em documentos como o CDC.

O conceito de que as políticas econômicas, geradoras de injustiça social, se colocam como responsáveis pelas condições de vida e saúde das populações não contempla, em absoluto, a culpa de um sujeito pelo insucesso de seu tratamento médico, devido a não ter seguido corretamente às orientações prescritas. Infelizmente, nota-se que, para o setor suplementar, o direito à saúde conquistado na Constituição Federal denota características de um "Estado paternalista" que “ignora deveres do indivíduo para com sua saúde” (CECHIN, 2008, p.16).

Talvez esta incoerência entre as concepções de saúde - que embasaram, por um lado a criação do SUS, refletindo a retomada das práticas de medicina social, encampadas por movimentos revolucionários e médicos progressistas, no século XIX e, a saúde suplementar, por outro, mantendo paradigmas impostos nos idos de 1960 através da forte compra de serviços médicos e especializados do setor privado, como garantidores de saúde - também seja fator primordial para a aparente dicotomia e competição existentes hoje entre os domínios público e privado, bem como a não complementariedade ou suplementariedade entre ambos.

Hoje, como se vê, a continuidade de fatores como o subfinanciamento do sistema público e os sucessivos incentivos governamentais às operadoras de planos de saúde têm colocado em risco o futuro do SUS, apontando a uma inversão total de valores se se considerar o SUS idealizado pela Reforma Sanitária, colocando na iminência de um Sistema "pobre para pobres e complementar para o setor privado" (PAIM, 2012, p. 612).

Neste sentido, é necessário ampliar a análise dos papéis dos governos brasileiros no atual cenário de saúde vivenciado no País. Afinal, nota-se que, mesmo tendo sido alterada a forma de regime ao longo do tempo, a tratativa dada à saúde pela maioria dos governos transitórios manteve-se similar àquela empregada desde antes da "Era Vargas", quando se designava aos profissionais médicos e ao serviço hospitalar o papel de garantidores de saúde.

Não se pode comparar a realidade política vivida no Brasil no período da ditadura, em estado de exceção, com o período de redemocratização. Contudo, é possível aproximar, vislumbrando incontáveis e infelizes semelhanças, as deliberações de saúde direcionadas pelo Estado em ambos os períodos. Devido a isso, pode-se pensar que exista uma hegemonia dominante na área da saúde brasileira que, mesmo com a conquista do direito conforme disposto da Constituição Cidadã, continuou e, aparentemente (se nada for feito no nosso sistema político), continuará trabalhando para a manutenção de antigos padrões de 'consumo de saúde', tratando manifestações sociais como biológicas, e medicalizando as vidas em desacordo com as políticas vigentes.

É sabido que um governo democrático representativo passa por algumas metamorfoses e is to faz parte, além do processo de amadurecimento de uma nação, de escolhas feitas pela sociedade civil organizada. Hoje, diferentemente do que ocorria há algumas décadas nos países ocidentais, os eleitores não necessariamente se identificam com um partido político específico, alterando seu padrão de voto de uma eleição para outra (MANIN, 1997). 
Pode-se pensar que o Brasil se configura em um misto político entre as democracias de público e de partido, sendo em ambas os representantes sempre eleitos pelo público (MANIN, 1997), porém coexistindo um misto entre negociações, discussões e deliberações entre os próprios partidos (característica da democracia de partido) e a presença da mídia, pesquisas de opinião e negociações com grupos de interesse suprapartidários (típicos da democracia de público). Sabe-se, infelizmente, que este misto brasileiro se torna nocivo à elaboração de políticas de Estado, pois os interesses de grupos específicos (que costumam financiar as campanhas mais exitosas) ditam as regras sobre quais políticas de governo, de interesse privado, serão postas em prática.

Num sistema político pautado pela lógica da 'troca de favores' - diretrizes de políticas de governo em troca do financiamento de campanhas - como ocorre no Brasil, pensar-se-ia que a democracia, então, não poderia mais ser chamada de representativa. Ao menos, não representativa como em sua significação essencial, de respeito aos interesses da nação. Nesta lógica imposta, tem-se um sistema que representa muito os interesses de poucos e, muito pouco, os interesses de muitos.

Na década de 1990, quando a democracia ainda era 'nova', iniciou-se no Brasil, com apoio popular através do poder do voto, o processo de entrada do projeto neoliberal no País. Este projeto foi iniciado pelo presidente Collor, um dos grandes responsáveis por inúmeros vetos na LOS, e implementado com maior vigor nos governos do Fernando Henrique Cardoso.

Foi ainda, na primeira gestão FHC, que um documento importante ao estudo da gênese da regulação ao setor suplementar é historicamente posto: o Plano Diretor de Reforma do Aparelho do Estado. Este documento, apesar de não conceber o mesmo valor jurídico de uma Lei, se faz tão ou mais importante que as demais analisadas neste estudo, pois foi através dele que o conceito de agência e a terceirização de serviços relacionados à área da saúde foram importados ao País como parte do projeto neoliberal a ser implementado.

A justificativa para existência deste Plano de Reforma se fundou na crise econômica enfrentada desde as décadas anteriores, na qual os níveis inflacionários figuravam entre um dos seus exemplos mais concretos. Conforme o documento, a crise econômica era, também, reflexo de uma crise do Estado brasileiro que tinha, dentre suas principais motivações, o "esgotamento da estratégia estatizante de intervenção do Estado” (BRASIL, 1995, p.10).

Assim, punha-se como inadiável para o governo em exercício a articulação de reformas econômicas que fossem “orientadas para o mercado", com vistas ao resgate da autonomia financeira do País e justificativa de resgate da capacidade para implementação de políticas públicas. Para tal feito, seria necessária a desburocratização do aparelho ${ }^{3}$ do Estado, bem como uma redefinição do seu papel, que deixaria de ser o "responsável" para ser o "regulador" do desenvolvimento econômico e social do País (BRASIL ,1995, p.11-12).

Neste ponto, já é possível notar um grau de incoerência entre o projeto de reforma do aparelho do Estado apresentado como diretriz dos governos deste período, para com o próprio projeto de Estado delimitado pela Constituição Federal, na qual se tinham responsabilidades e papel garantidor das políticas sociais e econômicas. Em suma, estas políticas seriam, logo, terceirizadas. Existindo tal disparidade entre o papel constitucional do Estado e a visão do governo na diretriz temporária do mesmo, seriam iminentes as desestruturações em setores de direitos conquistados, a exemplo da saúde. Quando se afirma neste documento que reformar o Estado significa "transferir

3 "Entende-se por aparelho do Estado a administração pública em sentido amplo, ou seja, a estrutura organizacional do Estado, em seus três poderes (Executivo, Legislativo e Judiciário) e três níveis (União, Estados-membros e Municípios)”. (BRASIL, 1995, p.12). 
para o setor privado as atividades que podem ser controladas pelo mercado” (BRASIL, 1995 p.12), o governo confirma sua visão do setor saúde como uma mercadoria, um produto a ser regulado.

No entanto, deixar de ser responsável para ser o regulador de serviços que, segundo a Constituição, deveriam ser garantidos pelo Estado, não seria um processo fácil. A este fenômeno de terceirização de responsabilidades estatais ocorridas com setores como a saúde, educação e cultura, deu-se o nome de "publicização", desta forma os serviços ficariam ainda vinculados ao setor público (por serem garantidos como direito conquistado), porém praticados de forma não estatal (BRASIL, 1995, p.13).

Considerando elementos importantes dispostos neste documento, em especial os papéis de regulador a ser assumido pelo Estado e a transferência de atividades para o setor privado a fim de serem reguladas pelo mercado, fica claro que a partir da década de 1990 o Estado brasileiro tomaria novo 'corpo', estabelecendo uma linha muito tênue e perigosa entre a melhoria na eficiência das estruturas públicas e dos serviços prestados e a quebra das conquistas de direitos sociais dispostas na Constituição Cidadã. Também devido a estas características de publicização de setores essenciais, como a saúde, é possível a efetivação de uma série de legislações futuras que regulariam esta prestação de serviços privados, a exemplo da própria Agência Nacional de Saúde Suplementar.

O próximo passo a ser dado no processo de conformação do Estado regulador estabelecido na década de 90 seria a Lei ${ }^{\circ} 9.656$ de 3 de junho de 1998, que dispõe sobre os planos e os seguros privados de assistência à saúde. Esta legislação ainda não efetiva uma agência reguladora para o setor, porém também se configura como um importante marco histórico à saúde suplementar, pois especifica em seu texto alguns conceitos utilizados até os dias de hoje no setor privado, a exemplo dos termos 'plano privado' e 'operadora' de assistência à saúde e 'carteira', referindo-se aos serviços para os beneficiários (BRASIL, 1998).

Passados 18 anos da promulgação desta lei, pode-se reconhecer que a regulamentação em si, do setor suplementar, somente ficou completa como se conhece hoje, a partir dos anos 2000, com a criação da ANS. A Lei 9.656/98 configura-se, portanto, como um dispositivo importante no mecanismo regulatório, mas se pode dizer que serve mais às próprias operadoras de planos de saúde do que à população em si, pois define os conceitos utilizados até os dias atuais de quem pode ou não e, ainda, de que forma 'comercializar' os produtos de prestação de serviços em saúde. Então, as legislações de 1998 e 2000 podem ser consideradas complementares uma a outra quando se estuda a origem histórica da regulação do setor privado, sendo de mais fácil compreensão a análise conjunta de ambas.

A Lei no 9.961, de 28 de janeiro de 2000, por sua vez, nasceu com o intuito de regular um setor ainda "sem padrão de funcionamento" (ANS, 2016). Isto significaria: ordenar, de alguma forma, a relação de consumo entre operadoras e beneficiários dos planos de saúde, estabelecendo limites e visando à fiscalização destes serviços.

Logo, a ANS surge a partir desta legislação em 2000, trazendo a grande responsabilidade de normatizar o setor privado, que fora garantido desde 1988, pseudo-explicado desde a LOS em 1990 e realizado pelos prestadores de serviço sem critérios, chegando ao ponto de utilizar-se o Código de Defesa do Consumidor para o pleito de direitos adquiridos pelos contratantes destes serviços. Devido a esta responsabilidade, a legislação em questão inclui como principal finalidade da instituição ANS a “defesa do interesse público na saúde suplementar” (BRASIL, 2000). 
Importante ressaltar que a ANS é criada pelo governo federal como sendo uma autarquia em regime especial, ou seja, é vinculada ao poder público (por ser um 'braço’ do Ministério da Saúde), mas com regimento e direcionamento próprios, a fim de conferir maior autonomia e agilidade nas decisões da Agência. Muitos dispositivos hoje conhecidos pelos beneficiários de planos de saúde, como o rol mínimo de procedimentos a serem cobertos pelos planos, bem como o tempo limite de espera para consultas e procedimentos, somente foram possíveis após a criação desta Agência em 2000.

É fato que, sendo a saúde complementar/suplementar parte do Sistema Único de Saúde, bem como seus beneficiários cidadãos também respaldados pelos direitos sociais conquistados na Constituição Federal, a vinculação entre o órgão regulador ANS e o Ministério da Saúde se justifique. Entretanto, quando se adentra à reflexão acerca das ações deste Ministério que, consequentemente, são reflexo das ações e da concepção de saúde dos governos federais em atuação no Brasil, o que se tem é um quadro incoerente, do ponto de vista epistemológico e legal. Incoerente, pois o sistema privado (seja suplementar ou complementar), hoje, aparenta receber mais benefícios que o próprio Sistema Público, cuja dona é a totalidade da sociedade brasileira.

Mesmo sendo a Agência reguladora uma autarquia em regime especial, é necessário que as gestões desta autarquia sirvam, de alguma forma, à sustentabilidade do Sistema Único de Saúde, sendo cumprindo seu papel apenas de disponível para a livre escolha do cidadão, sendo na complementação das estruturas momentaneamente insuficientes do Sistema ou, ainda, suplementando um SUS já bem-estruturado. Talvez, se qualquer uma destas opções fossem atendidas, poder-se-ia reconhecer que a Agência cumpre sua finalidade de garantia de interesse público.

Contudo, em uma realidade política na qual o SUS recebe uma verba inferior (em percentual do PIB) àquela recebida pelo setor privado, nota-se a contradição como motor da história capitalista (GRAMSCI, 1981). No entanto, esta compreensão não destitui a indignação: a) De quem é a responsabilidade sobre esta incoerência?; b) Da Agência?; c) Ou do Ministério da Saúde e dos governos federais, que vêm fomentando, historicamente, independente da regulação, a iniciativa privada na saúde?; d) Ou seria, também, da falta de mobilização civil de resistência?

O que se vê, então, é uma sucessão (salvo raros momentos) de gestões ministeriais compostas por grupos hegemônicos interessados na mercantilização da saúde. Isto se prova com a recente liberação da entrada de capital estrangeiro no setor, aproximando-se diretamente dos interesses das empresas privadas, a exemplo de planos de saúde e das indústrias farmacêuticas. Logo, isso nada se parece com uma gestão comprometida com o Sistema Único de Saúde (COSTA; RIZOTTO, 2015).

Passados, então, 25 anos da Lei Orgânica da Saúde e mais de 15 desde assinatura da Lei que oficializa a existência da Agência Nacional de Saúde Suplementar no Brasil, algumas questões referentes ao real papel da iniciativa privada para com o poder público ainda ficam pendentes e, infelizmente, grande parte destes questionamentos caminham de mãos dadas às ações de regulação realizadas pela ANS que, por sua vez, estão alinhadas à visão política do Ministério da Saúde.

É triste pensar que o SUS da atualidade "não tem financiamento, gestão, utopia, ninguém que acredite nisso" (CUETO, M. et al., 2014, p. 98). O peso destas palavras reforça o pensamento investigativo sobre o que a Legislação do setor realmente quer dizer com 'defesa do interesse público' e, ainda, de que maneira este termo tem sido utilizado ao longo dos anos para solidificação da iniciativa privada no cenário nacional de saúde. Mais do que a responsabilidade de um governo específico pelos 
problemas de saúde brasileiros e pela inconsistência prática e conceitual da relação entre público e privado, é necessário repensar, com urgência, o sistema político que permite que isto ocorra.

Em linhas gerais o que está posto hoje no misto entre democracia de público e de partido e na ausência de democracia representativa é um sistema político que permite que grupos específicos (aí, leiam-se: indústrias farmacêuticas, operadoras de planos de saúde, dentre outros) financiem campanhas políticas. Campanhas de pessoas que futuramente serão os responsáveis por legislar sobre nossas condições econômicas, sociais e de saúde. Ora, se nada no Brasil é de graça e a tudo ‘dá-se um jeitinho’, estas dívidas de campanhas serão um dia cobradas e, infelizmente, continuarão sendo pagas pela maioria dos políticos à custa da dignidade do povo brasileiro.

A pergunta que não quer calar se mantém viva e pulsante: voltando-se para o estudo do financiamento do SUS e das ações direcionadas à saúde suplementar, como tamanha incoerência é possível?! No entanto, ela necessariamente exige o acompanhamento de outra pergunta: até que ponto a sociedade civil está organizada, mobilizando na superação destes padrões hegemônicos impostos pelas elites políticas brasileiras desde a década de 1920? Sem esta reflexão coletiva, sem ações para superação desta subalternidade que aliena cidadãos na aceitação, passividade e conivência, será muito difícil lutar por interesse público na saúde.

\section{CONSIDERAÇÕES FINAIS}

O presente estudo operacionalizou-se por meio de pesquisa documental realizada através da análise de documentos legais, infralegais e marginais relacionados à origem e à oficialização do setor suplementar, representado na figura de sua Agência reguladora - ANS em recorte histórico de 1985 a 2000. Intencionou-se, com esta pesquisa qualitativa, analisar os sentidos atribuídos ao termo 'interesse público’ na saúde no contexto da saúde suplementar.

Em uma perspectiva histórica, verificou-se que o setor privado, como se dispõe hoje em nosso País, é produto de políticas públicas hegemônicas, realizadas desde a Lei Eloy Chaves, de 1923, que instituiu as CAPs, passando pela lógica privatista da compra de serviços médicos hospitalares fomentados na ditadura militar e culminando na regulação do setor com a entrada do projeto neoliberal nos governos Collor e, em especial, FHC.

Notou-se que, apesar das metamorfoses políticas sofridas pelo Estado brasileiro, considerando as transições entre República Velha, "Era Vargas", ditadura militar eredemocratização, as práticas de saúde direcionadas pelos governos transitórios responsáveis pelas diretrizes do Estado durante estes períodos não tiveram alterações significativas de paradigmas, tampouco em suas concepções de saúde.

Considerando esta construção histórica do setor saúde no Brasil, em especial as condutas governamentais referentes ao domínio privado, emergiu neste estudo Mercadoria como categoria analítica, pois os documentos legais utilizados para remonte da história da saúde suplementar demonstraram a convergência das ações políticas de privilégio ao setor privado. Conforme verificado, preteriu-se a instituição de políticas de Estado realmente condizentes com as necessidades da população em favor do incentivo à 'compra' de serviços médicos, especializados e farmacológicos como resolução para os problemas de saúde da população.

Hoje, mesmo com o advento do SUS, resultado direto na militância do Movimento da Reforma Sanitária na retomada do pensamento da medicina social, ainda se tem como concepção 
hegemonizada no aparato midiático brasileiro a lógica do processo saúde-doença como resultado de ações biológicas e não sociais. Ou seja, nesta lógica imposta ao povo, a bactéria ainda se configura como principal inimiga da saúde e não as políticas econômicas de desigualdade, que impossibilitam aos cidadãos o mínimo de dignidade de vida. Nas legislações verificadas, clarificou-se a tratativa da saúde como uma mercadoria ao longo da história do nosso País. Desta forma, mesmo com o direito à saúde conquistado na Constituição Cidadã, a liberdade de ação da iniciativa privada no setor e sua futura regulação, sob a justificativa da liberdade de escolha, aparentam ser o plano principal dos interesses privados garantidos mediante políticas de governo, e não a complementariedade constitucional ao Sistema Universal como política de Estado.

A possibilidade de tratar a saúde como uma mercadoria, e não como um direito, pode ser reflexo do sistema político vigente no Brasil, no qual as democracias de partido e de público se fundem, em um misto perigoso representativamente, no qual a força da mídia e o financiamento privado de campanhas garantem que aquela hegemonia privatista nunca se desfaça, sendo a cada dia mais rotineira a 'compra de saúde’ em balcões de farmácias.

Para reversão desta situação controversa e injusta socialmente, é necessário que a população brasileira se una e busque seu fortalecimento como sociedade civil organizada, a fim de superar a condição de subalternidade historicamente imposta ao povo, subjugado por políticas de interesse privado respaldadas pelo apelo da mídia direcionada e oficializadas por um sistema eleitoreiro cuja moeda de troca é a dignidade do cidadão.

Nota-se, no entanto, que a abertura do Estado no neoliberalismo e, com efeito, ao conceito de agência importado por um projeto de reforma não é exclusividade brasileira. Conforme verificado, assim como ocorreu com a concepção de saúde impressa na Constituição Federal pela reforma sanitária brasileira, países como a Itália também sofreram derrotas sociais ao verem reformas administrativas neoliberais subvertendo os papéis de atuação do Estado como responsáveis pelas condições de saúde de suas populações.

Assim, talvez não fosse a reforma brasileira a grande responsável pelo tratamento mercadológico dispensado à saúde e ao seu interesse público, de forma incoerente ao papel do Estado, mas sim algo maior. Algo que se sobrepõe não só ao Estado e ao governo brasileiro, mas também de várias outras nações, impondo a lógica de regulação de mercado acima de qualquer direito social. Seria, esta conduta, talvez, responsabilidade do próprio sistema ao qual se optou por seguir.

A busca por sentidos atribuídos ao termo “interesse público” na saúde, pela saúde suplementar, convergiu para um único sentido, o sentido atribuído pelo próprio capital, na representação de mercadoria, traduzindo em uma única palavra como a saúde vem sendo tratada no Brasil historicamente.

\section{REFERÊNCIAS}

BRASIL. Agência Nacional de Saúde. ANS: Histórico. Disponível em: <http://www.ans.gov.br/index. php/aans/quem-somos/historico> Acesso em: 26 mai. 2016.

BRASIL. Lei No 9.656, de 03 de junho de 1998. Brasília, o3 jun. 1998.

BRASIL. Lei No 8.078, de 11 de setembro de 1990. Brasília, 11 set. 1990.

BRASIL. Lei No 8.080, de 19 de setembro de 1990. Brasília, 19 set. 1990. 
BRASIL. Constituição da República Federativa do Brasil de 1988. Brasília, O5 out. 1988.

BRASIL. Plano Diretor de Reforma do Aparelho do Estado. Brasília, 21 set. 1995.

BRASIL. Lei $\mathbf{N}^{\mathbf{0}} \mathbf{9 . 9 6 1}$, de 28 de janeiro de 2000. Brasília, 28 jan. 2000.

BRASIL. AGÊNCIA NACIONAL DE SAÚDE SUPLEMENTAR. Caderno de Informação da Saúde Suplementar: Beneficiários, Operadoras e Planos. 2015.

CAVICCHI, I. La Sanità. Bari: Dedalo, 2005.

CECHIN, J. A história e os desafios da saúde suplementar: 10 anos de suplementar: 10 anos de regulação. IESS: São Paulo, 2008 Disponível em: <http:// http://www.iess.org.br/html/Roche5set2008. pdf > Acesso: 31 maio 2016.

COSMACINI, G. Storia della Medicina e della Sanità in Italia. Roma: Laterza, 2005.

COSTA, A. M.; RIZZOTTO, M. L. F. Os direitos sociais e o SUS são essenciais ao povo brasileiro. Saúde em Debate, Rio de Janeiro, v. 39, n. 106, p. 576 - 581, jul./set. 2015.

CUETO, M. et al. Pensar o Sistema Único de Saúde do século XXI: entrevista com Lígia Bahia. História, Ciências, Saúde - Manguinhos, Rio de Janeiro, v.21, n.1, p.93-107, jan./mar. 2014.

DA ROS, M. A. Fleck e os estilos de pensamento em saúde pública: um estudo da produção da FSPUSP e ENSP-FIOCRUZ, entre 1948 e 1994. 2000. 207f. Tese (Doutorado em Educação), Universidade Federal de Santa Catarina, Florianópolis. 2000.

DE MARTINO, E. Etnologia e cultura nazionale negli ultimi dieci anni. Società, ano IX, n. 3, p. 313-342, 1953.

GRAMSCI, A. A Concepção Dialética da História. 4. ed. Rio de Janeiro: Civilização Brasileira, 1981.

IDEC. ABC do Consumidor: Direitos na compra e troca de produtos. [S. I.]. Disponível em: <http:// www.idec.org.br/trocadeproduto/carta/160513-cart-idec-trocaproduto.pdf>. Acesso em: 09 mar. 2017.

MANIN, B. The Principles of Representative Government. Cambridge: Cambridge University Press, 1997.

MAPELLI, V. Il Sistema Sanitário Italiano. Bologna: Il Mulino, 1999.

MERCADANTE, O. A. (Coord.). Evolução das políticas e do sistema de saúde. In: FINKELMAN, J. (Org.) Caminhos da saúde no Brasil. Rio de Janeiro: Fiocruz, 2002. Disponível em: <http://books.scielo. $\mathrm{org} / \mathrm{id} / \mathrm{sd} / \mathrm{pdf} /$ finkelman-9788575412848-05.pdf>. Acesso em: 27 maio 2016.

MICHAELIS. Dicionário de Português Online. Disponível em: http://michaelis.uol.com.br/moderno/ portugues/index.php?lingua=portugues-portugues\&palavra=mercadoria. Acesso: 19 jun. 2016

OLIVEIRA, J. A. de A.; TEIXEIRA, S. M. F. (IM)Previdência Social: 60 anos de história da Previdência no Brasil. 2. ed. Petrópolis: Vozes/Associação Brasileira de Pós-Graduação em Saúde Coletiva, 1989.

PAIM, J. S. O futuro do SUS. Cadernos de Saúde Pública, Rio de Janeiro, v. 28, n. 4, p. 612 - 613, abr. 2012.

PAIM, J. S.; TEIXEIRA, C. F. Configuração institucional e gestão do Sistema Único de Saúde: problemas e desafios. Ciência \& Saúde Coletiva, Rio de Janeiro, v. 12, p. 1819 - 1829, nov. 2007.

REIS, D. O.; ARAÚJO, E. C; CECÍLIO, L. C. de O. Políticas Públicas de Saúde no Brasil: SUS e Pacto 
pela Saúde. [S. I.]. Disponível em: <http://www.unasus.unifesp.br/biblioteca_virtual/esf/1/modulo_ politico_gestor/Unidade_4.pdf $>$. Acesso em: 09 mar. 2017.

SANTOS, L. Aspectos do financiamento das ações e dos serviços de saúde no SUS: Seguro Saúde e outras modalidades de Medicina Supletiva. Saúde em Debate, Rio de Janeiro, v. 37, p.26-30, dez. 1992.

SILVA, K. L.; RODRIGUES, A. T. Promoção da saúde no âmbito da saúde suplementar: relações e tensões entre operadoras, beneficiários e agência reguladora estatal. Saúde e Sociedade, São Paulo, v. 24, p.193204, 2015.

SOUZA, R. M. L. de. O mercado de Saúde Suplementar no Brasil. Regulação e resultados econômicos dos planos privados de saúde. 2014. 296f. Tese (Doutorado em Políticas Públicas, Estratégias e Desenvolvimento), Universidade Federal do Rio de Janeiro, Rio de Janeiro. 2014.

UNIVERSITÀ DEL VOLONTARIATO. Terzo Settore: contesto d'appartenenza e bisogni formativi. 2001. Disponível em: <http://www.ciessevi.org/sites/default/files/pubblicazioni/universita/Udv_ Terzosettore.pdf> Acesso em: 12 jun. 2016.

VIGOTSKI, L. S. A Construção do Pensamento e da Linguagem. São Paulo: Martins Fontes, 2001.

WEINGÄRTNER, V. Responsabilidade civil do paciente. 2012. Disponível em: <http://www.egov. ufsc.br/portal/conteudo/responsabilidade-civil-do-paciente>. Acesso em: 28 mai. 2016.

WERNECK, H. F. Os Seguros privados de saúde no Brasil: uma análise taxonômica a partir da OCDE. 2010. Disponível em: < http://www.ans.gov.br/images/stories/Materiais_para_pesquisa/ Materiais_por_assunto/ProdEditorialANS_Textos_para_discussao_02.pdf > Acesso em: 10 mar. 2017. 
54 - RBTS - v.3, n.2, 2016

Alves \& Lima 
RBTS, v.3, n.2, $2016-55$

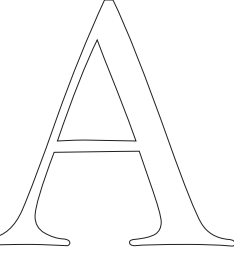

